\title{
Real-Time Noninvasive Analysis of Biocatalytic PET Degradation
}

Ronny Frank ${ }^{a}$, Dana Krinke ${ }^{a}$, Christian Sonnendecker ${ }^{b}$, Wolfgang Zimmermann ${ }^{b}$, Heinz-Georg Jahnke ${ }^{a *}$

${ }^{a}$ Centre for Biotechnology and Biomedicine, Molecular biological-biochemical Processing Technology, Leipzig University, Deutscher Platz 5, D-04103 Leipzig, Germany

bInstitute of Analytical Chemistry, Leipzig University, Johannisallee 29, D-04103 Leipzig, Germany

*Email: heinz-georg.jahnke@bbz.uni-leipzig.de 


\section{Supplementary Tables}

Tab.S1: Surface increase factors extracted from AFM images of G-PET hydrolysed by LCC and PHL7. Surface increase factor is calculated as ratio of the surface area and the projected area. Shown are the single and mean values, corresponding to Figure 2 and S7.

\begin{tabular}{|c|c|c|c|c|}
\hline time / h & \multicolumn{4}{|c|}{ size $60 \times 60 \mu \mathrm{m}^{2}$} \\
\hline \multirow{3}{*}{0} & \multirow{2}{*}{\multicolumn{2}{|c|}{$\begin{array}{c}\text { untreated } \\
1.001,1.000,1.000 \\
1.001,1.001,1.003\end{array}$}} & \multirow{2}{*}{\multicolumn{2}{|c|}{$\begin{array}{c}\text { mean } \pm \text { sd } \\
1.001 \pm 0.001\end{array}$}} \\
\hline & & & & \\
\hline & LCC & mean $\pm s d$ & PHL7 & mean $\pm s d$ \\
\hline 2.5 & $\begin{array}{c}1.013,1.023 \\
1.019\end{array}$ & $1.018 \pm 0.005$ & $\begin{array}{c}1.025,1.028 \\
1.024\end{array}$ & $1.026 \pm 0.002$ \\
\hline 5.0 & $\begin{array}{c}1.015,1.021 \\
1.022 \\
\end{array}$ & $1.019 \pm 0.004$ & $\begin{array}{c}1.012,1.010 \\
1.009\end{array}$ & $1.010 \pm 0.001$ \\
\hline 7.5 & $\begin{array}{c}1.020,1.027, \\
1.018,1.011, \\
1.017\end{array}$ & $1.019 \pm 0.005$ & $\begin{array}{c}\text { 1.009, 1.010 } \\
1.011\end{array}$ & $1.010 \pm 0.001$ \\
\hline 10.0 & $\begin{array}{c}1.017,1.016 \\
1.018\end{array}$ & $1.017 \pm 0.001$ & $1.013,1.012$ & $1.013 \pm 0.001$ \\
\hline 15.0 & $\begin{array}{c}1.015,1.016 \\
1.018\end{array}$ & $1.016 \pm 0.002$ & & \\
\hline mean [5-10] & & $1.018 \pm 0.001$ & & $1.011 \pm 0.001$ \\
\hline time / $\mathrm{h}$ & \multicolumn{4}{|c|}{ size $2 \times 2 \mu \mathrm{m}^{2}$} \\
\hline \multirow[t]{2}{*}{0} & \multicolumn{2}{|c|}{$\begin{array}{c}\text { untreated } \\
1.001,1.001\end{array}$} & \multicolumn{2}{|c|}{$\begin{array}{c}\text { mean } \pm \text { sd } \\
1.001 \pm 0.000\end{array}$} \\
\hline & LCC & mean $\pm s d$ & PHL7 & mean $\pm s d$ \\
\hline 2.5 & $\begin{array}{c}1.248,1.298, \\
1.289,1.291\end{array}$ & $1.281 \pm 0.023$ & $\begin{array}{l}1.146,1.124, \\
1.106,1.119, \\
1.087,1.085\end{array}$ & $1.111 \pm 0.024$ \\
\hline 5.0 & $1.137,1.123$ & $1.130 \pm 0.010$ & $\begin{array}{l}1.120,1.119 \\
1.109,1.118\end{array}$ & $1.116 \pm 0.005$ \\
\hline 7.5 & $\begin{array}{c}1.140,1.129 \\
1.173\end{array}$ & $1.147 \pm 0.023$ & $\begin{array}{l}1.098,1.097 \\
1.097,1.090\end{array}$ & $1.095 \pm 0.004$ \\
\hline 10.0 & $1.062,1.078$ & $1.070 \pm 0.011$ & $1.115,1.117$ & $1.116 \pm 0.001$ \\
\hline 15.0 & $1.178,1.134$ & $1.156 \pm 0.031$ & & \\
\hline mean [5-10] & & $1.116 \pm 0.04$ & & $1.109 \pm 0.012$ \\
\hline
\end{tabular}




\section{Supplementary Figures}

A

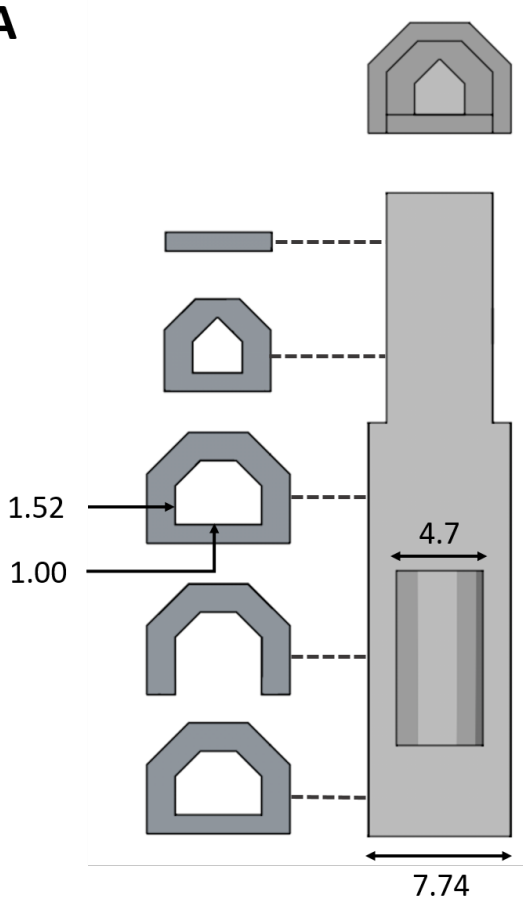

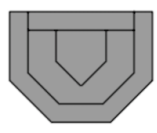
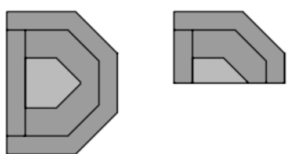

B
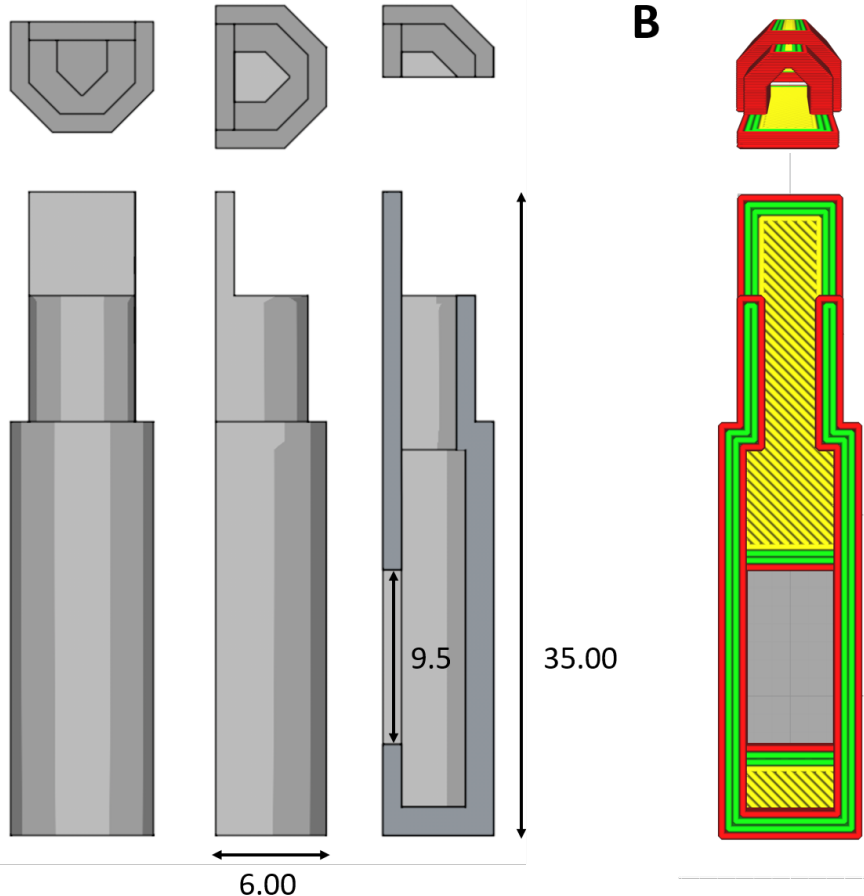

Fig.S1: Geometry of the 3D-printed polypropylene insert. A Top, frontal, side and back views from the insert and cross sections. PET window $\left(4.7 \times 9.5 \mathrm{~mm}^{2}\right)$ is $4.3 \times 9.1 \mathrm{~mm}^{2}$ after printing with a $0.4 \mathrm{~mm}$ nozzle on an Ultimaker 3.0 Extended. B Cura 4.8 preview of the sliced insert. Numerical data in $\mathrm{mm}$.

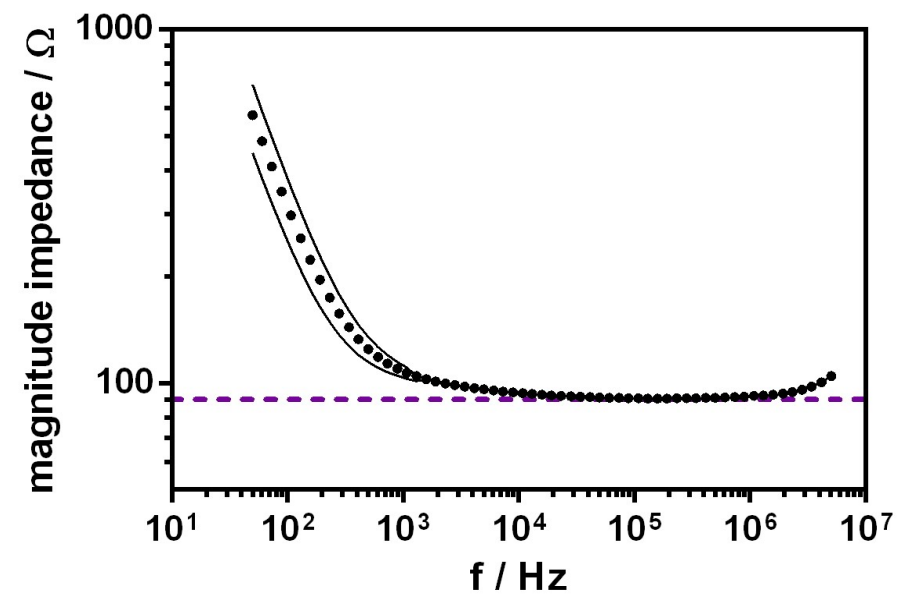

Fig.S2: Impedance spectrum of an "open" reaction window. Dashed line marks base resistance of the measurement system of $90 \Omega(=\mathrm{R} 1)$. Impedance spectra was fitted to an equivalent circuit model of a 
double-layer capacitance $C_{d l}$ in series with a resistance $R 1 . C_{d l}$ was determined to be $5.63 \mu F$, which is five orders of magnitude higher compared to the case of a "PET-closed" reaction window. Thus, its contribution to the impedance signal during a PET-degradation experiment is negligible. Mean \pm sd $(n=4)$
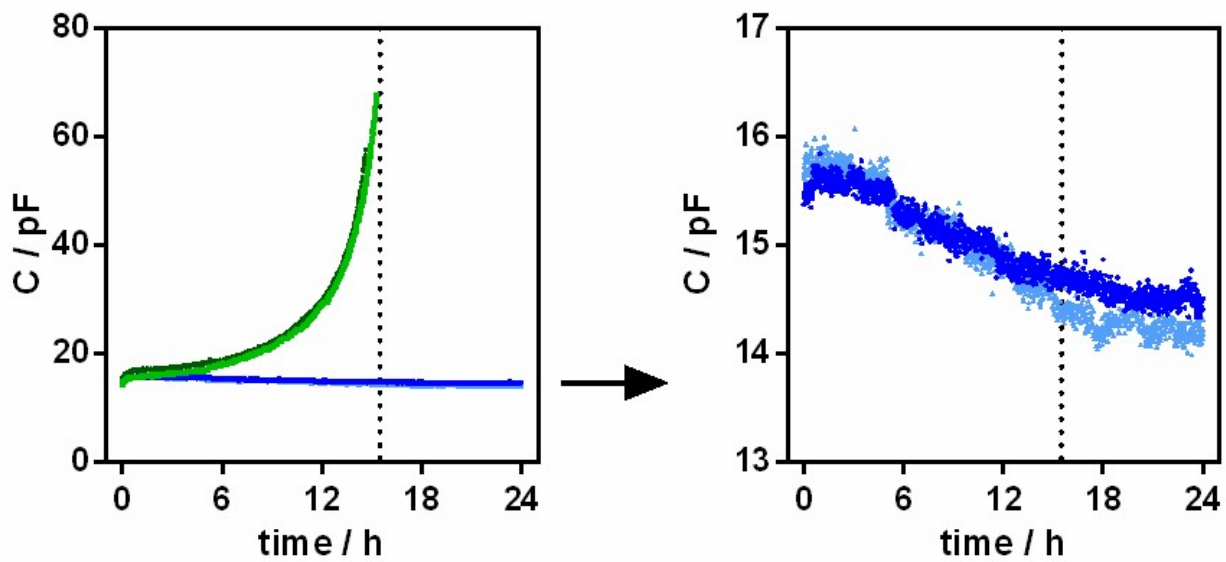

Fig.S3: Change in capacitance with and without PHL7. Data for G-PET film hydrolysis with $13.9 \mu \mathrm{g} \cdot \mathrm{mL}^{-1}$ PHL7 (green graphs) and negative controls without enzyme (blue graphs) are shown.

A

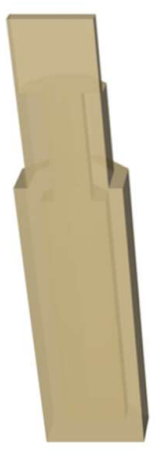

0

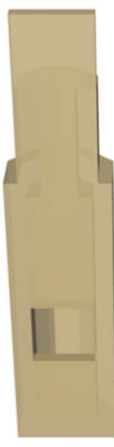

0.5

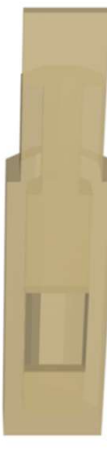

0.75

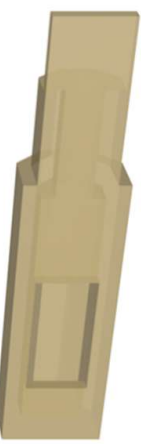

1
B

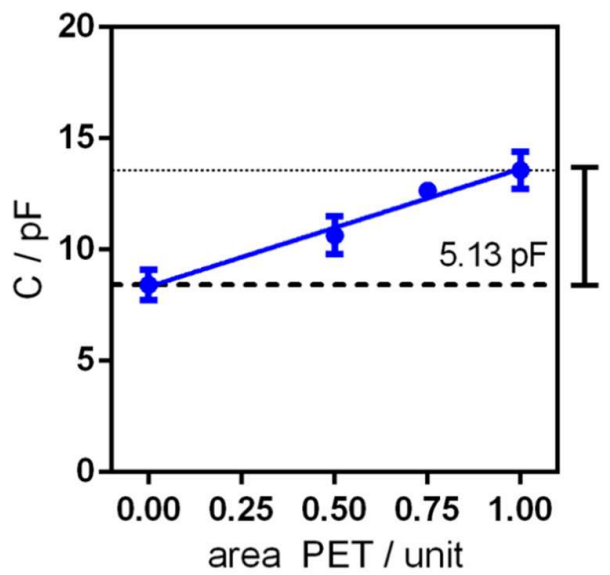

Figure S4: Determination of the G-PET film capacitance using inserts with variable PET windows at $70^{\circ} \mathrm{C}$ in enzyme-free reaction buffer. A PP inserts with different sized reaction windows, specified with 
size factor to the original insert. B Capacitance of the PET film in the reaction setup is $5.1 \mathrm{pF}$ based on linear regression. This value fitted well with a theoretically calculated value, assuming a slightly higher relative permittivity of $3.3\left(70^{\circ} \mathrm{C}\right)$, compared with the manufacturer's specification of $3.0\left(25^{\circ} \mathrm{C}\right)$ in accordance with the temperature difference. The change in size of the PET reaction window caused also a slight change in the size of the PP insert and thus $\mathrm{C}_{\text {rest. }}$.
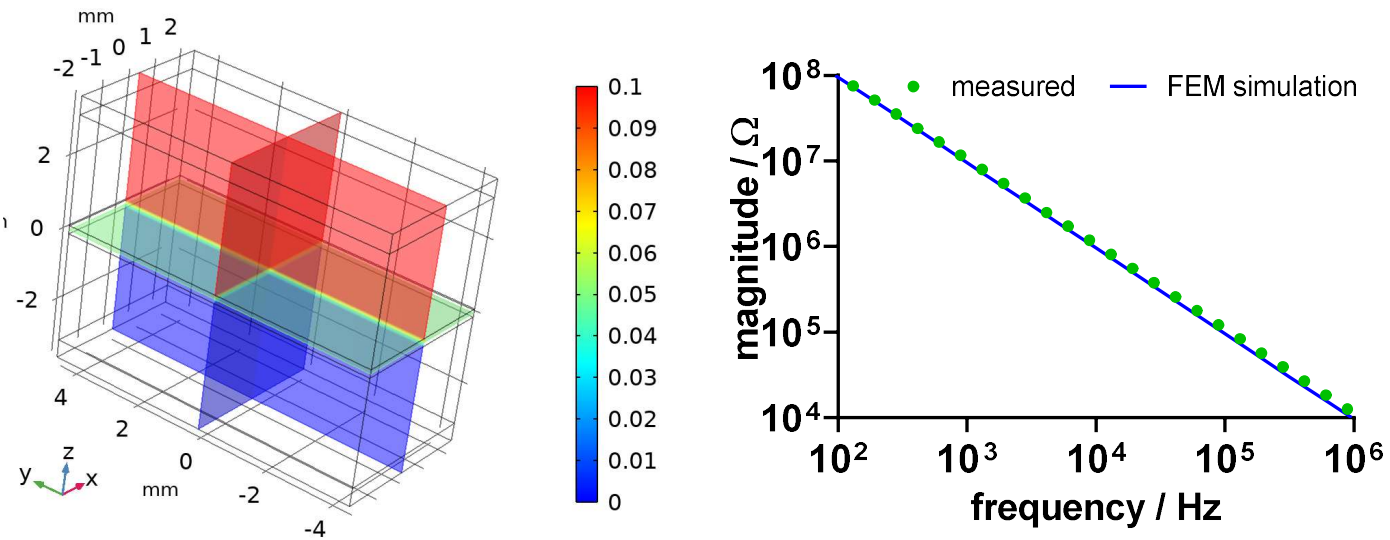

Figure S5: FEM simulation of PET film. The PET film was simulated with dimensions of $4.3 \times 9.1 \mathrm{~mm}^{2}$, a thickness of $225 \mu \mathrm{m}$ and a relative permittivity of 3.3 (left). The derived impedance magnitude spectrum correlates well with the experimental data (right).

A

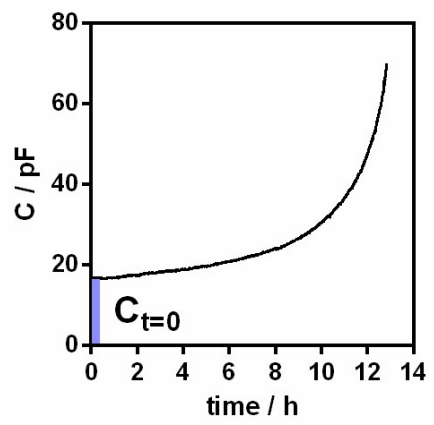

B

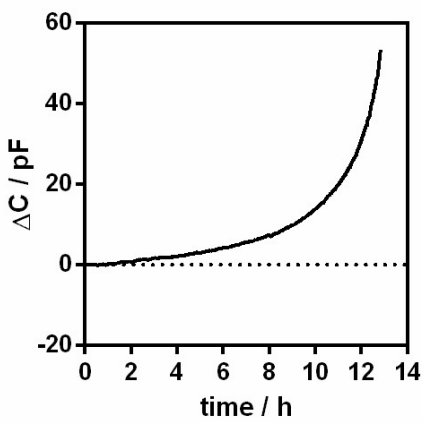

C

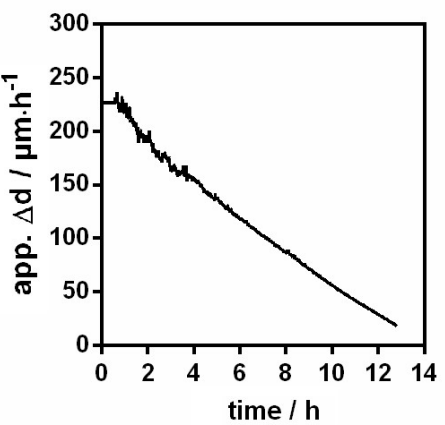

Fig.S6: Translation of the capacitance into G-PET film thickness. A Capacitance determined by an equivalent circuit model. B Pure capacitance change over time. C Calculated film thickness using a default value of the PET film derived by mechanical measurement. 

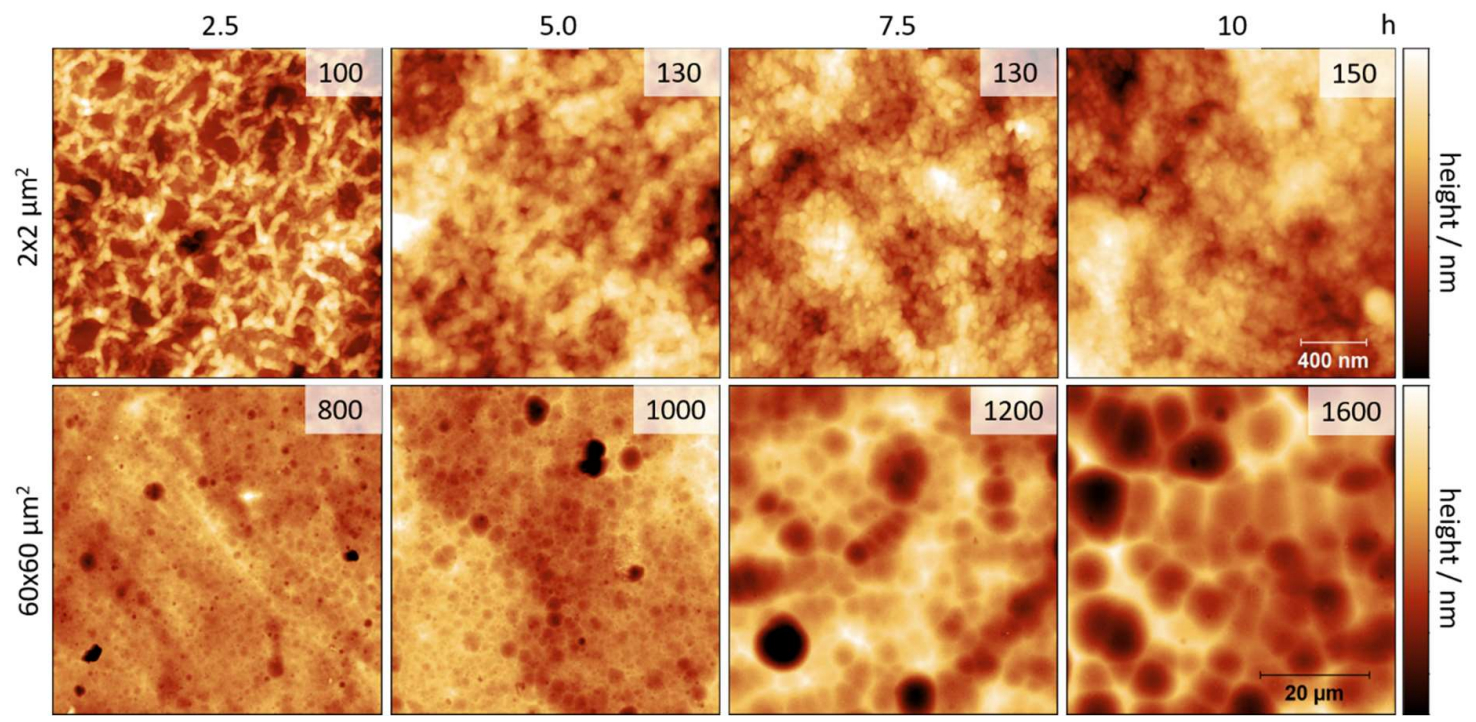

Figure S7: Topographic images of LCC-degraded PET samples. LCC-degraded PET samples were imaged

by intermittent contact AFM after $2.5 \mathrm{~h}, 5 \mathrm{~h}, 7.5 \mathrm{~h}$ and $10 \mathrm{~h}$ of incubation on areas of $2 \times 2 \mu \mathrm{m}^{2}$ and $60 \times 60 \mu \mathrm{m}^{2}$. Height scales is given in linear range from zero to the value in the upper right corner of each image.

A
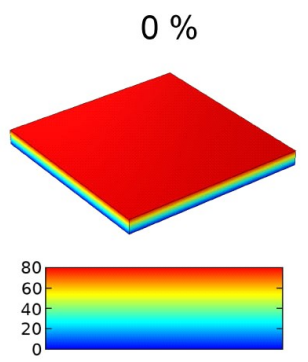

B

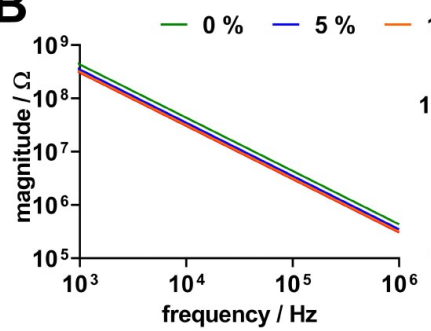

surface increase
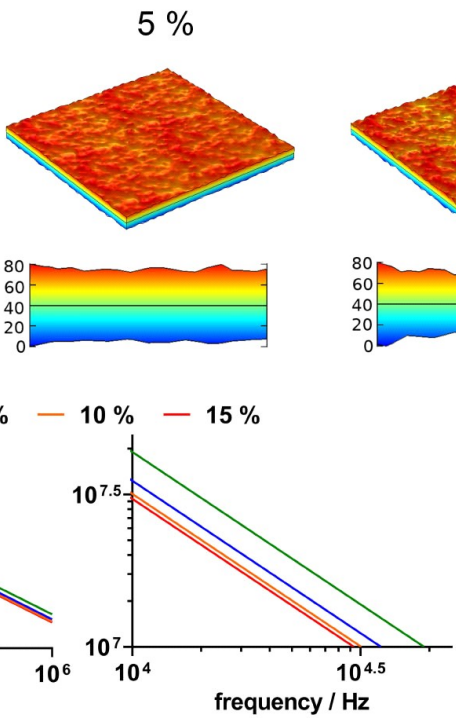

$10 \%$
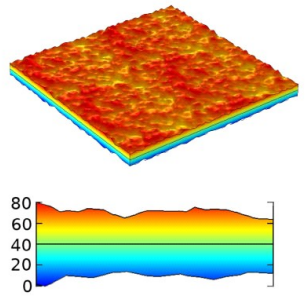

C

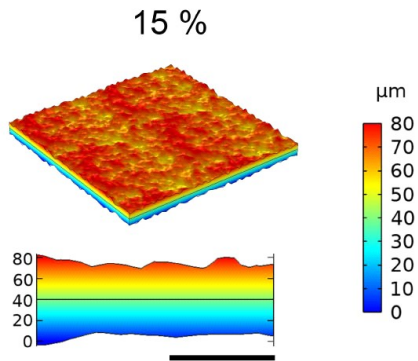

\begin{tabular}{lrrrr}
\hline & $\mathbf{0} \%$ & $\mathbf{5 \%}$ & $\mathbf{1 0} \%$ & $\mathbf{1 5 \%}$ \\
\hline Cap. / C $\left(1 \mathrm{~mm}^{2}\right)$ & $3.6 \mathrm{E}-13$ & $4.6 \mathrm{E}-13$ & $5.0 \mathrm{E}-13$ & $5.2 \mathrm{E}-13$ \\
Cap. / C $\left(39.1 \mathrm{~mm}^{2}\right)$ & $1.41 \mathrm{E}-11$ & $1.80 \mathrm{E}-11$ & $1.96 \mathrm{E}-11$ & $2.03 \mathrm{E}-11$ \\
ratio (to 0 \%) & $\mathbf{1 . 0 0}$ & $\mathbf{1 . 2 8}$ & $\mathbf{1 . 3 9}$ & $\mathbf{1 . 4 4}$ \\
\hline
\end{tabular}

Figure S8: FEM simulation for investigation of surface increase effect on PET film capacitance. A To overcome computation limits, the simulation was performed with PET film dimensions of $1 \times 1 \mathrm{~mm}^{2}$. 
The initial PET film thickness was set to $80 \mu \mathrm{m}$ according to the final optical/mechanical measurements after $10 \mathrm{~h}$ (see Fig. 2A). The surface area was increased by $5 \%, 10 \%$ and $15 \%$ while keeping the maximum film thickness at $80 \mu \mathrm{m}$ (cross section, scale bar $=100 \mu \mathrm{m}$ ). B The FEM simulation derived impedance magnitude spectra revealed the surface increase dependent decrease of the impedance magnitude. C Based on the FEM simulation derived impedance magnitude spectra, the PET film capacitance was determined by equivalent circuit fitting (simulated area of $1 \times 1 \mathrm{~mm}^{2}$ ). Furthermore, the capacitance of the measured PET film $\left(4.3 \times 9.1 \mathrm{~mm}^{2}\right)$ as well as the capacitance ratio was calculated.
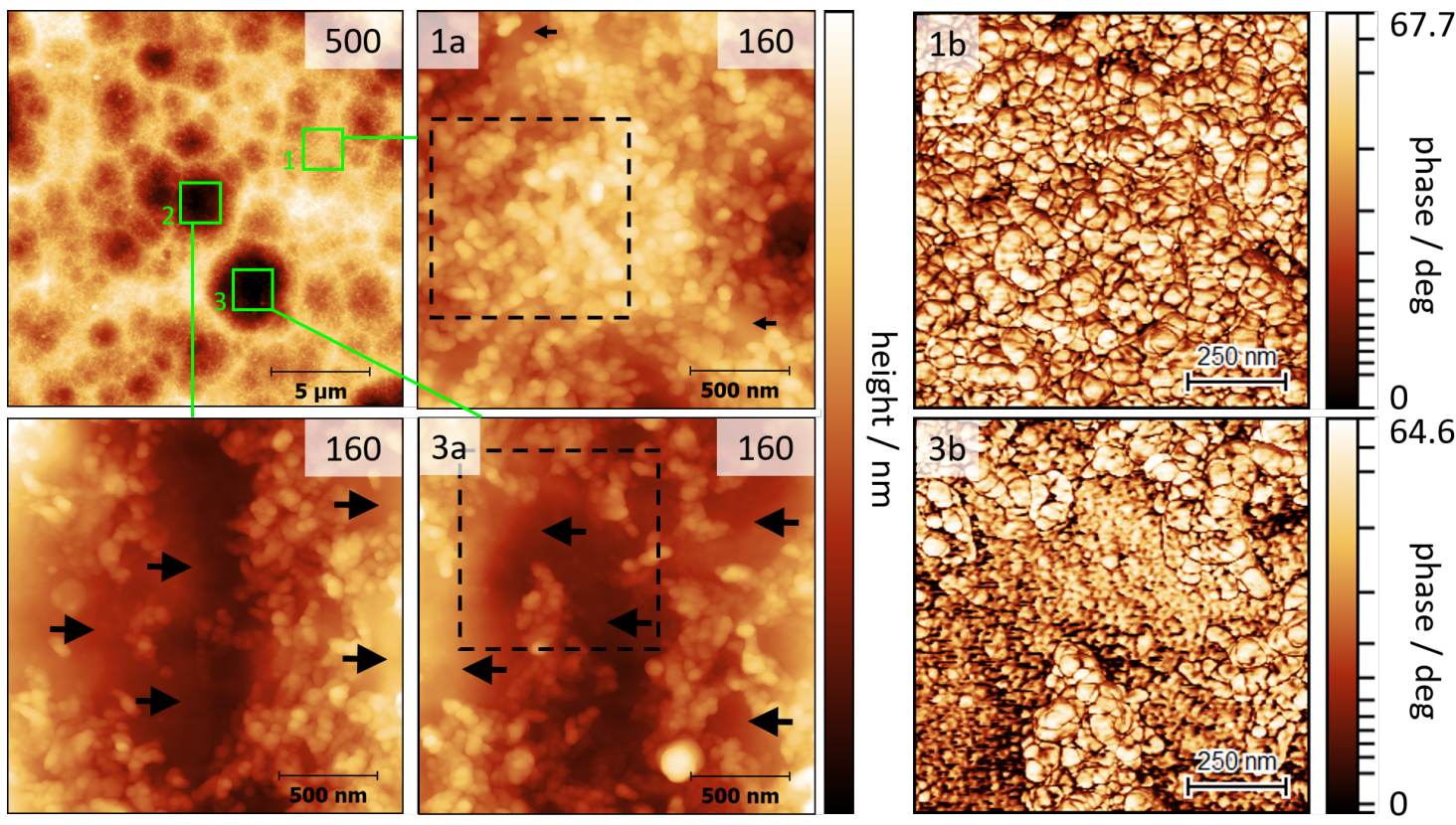

Fig.S9: Surface of the G-PET film after $2.5 \mathrm{~h}$ degradation by PHL7 analyzed by intermittent-contact atomic force microscopy. Especially in regions of depressions at the bottom of degradation craters, a high content of low roughness and low curvature areas were detected (arrows). Squares marked in green in the upper left image show enlarged areas. Height scales range from zero to the value indicated in the upper right corner of each image in $\mathrm{nm} .1 \mathrm{~b}$ and $3 \mathrm{~b}$ show enlarged areas (dashed squares) of the lock-in phase signal of the corresponding height image. 


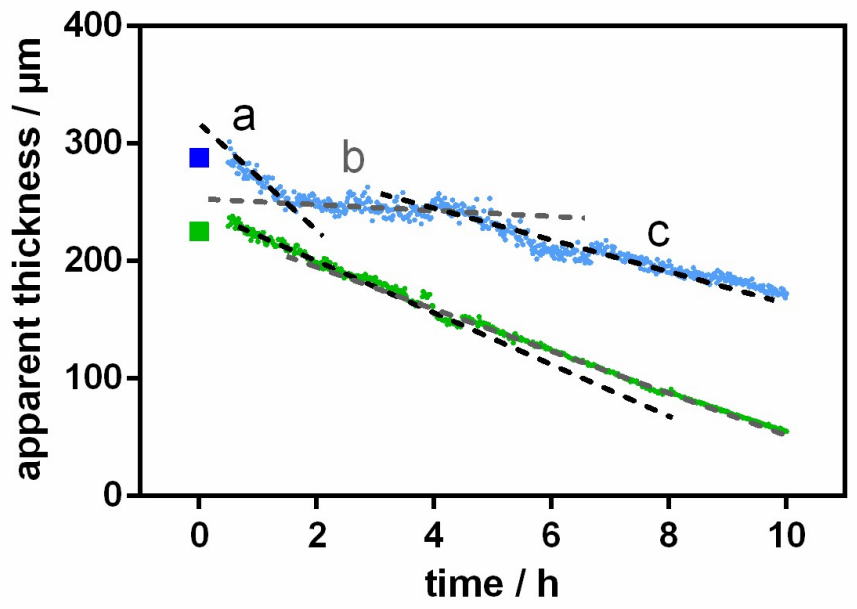

Fig. S10: Degradation of R-PET film from a post-consumer PET thermoform clamshell packing and a G-PET film. Blue: R-PET, green: G-PET. Squares mark thickness values of the mechanical measurement, while circles mark thickness values derived from impedance data. In case of the R-PET film, three distinct degradation time zones could be observed. Especially noticeable is zone b, where a particularly slow degradation took place after a very high apparent thickness decrease in zone a. In contrast, the G-PET film only sparely showed a zone formation.
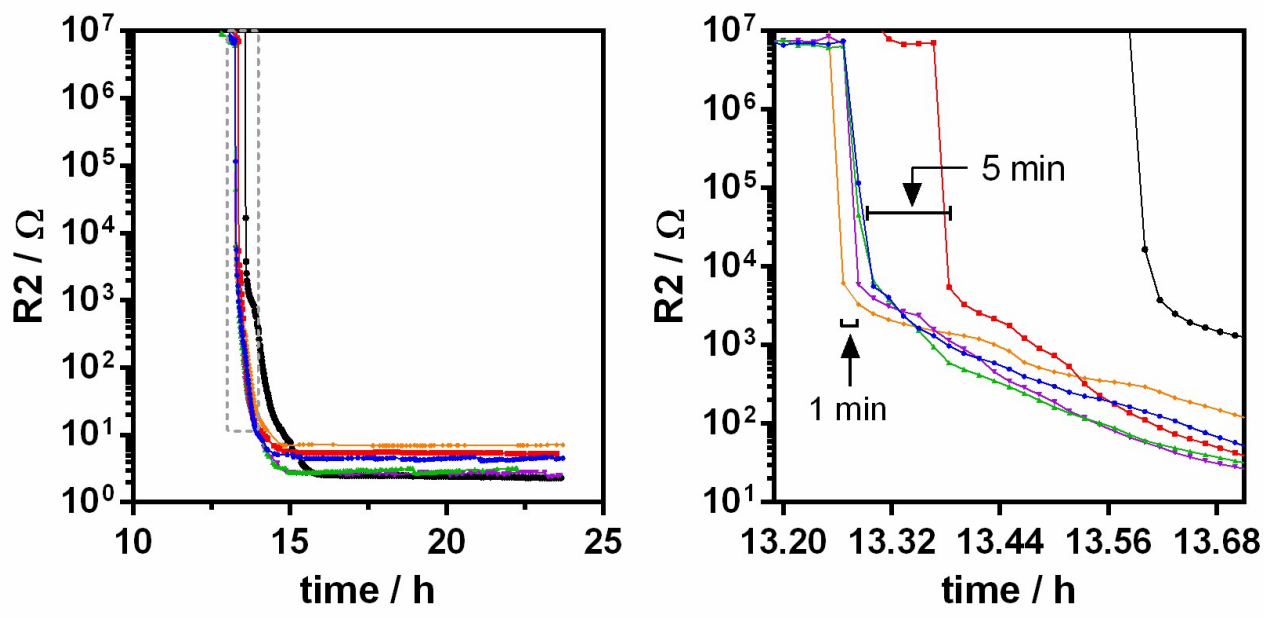

Fig. S11: Deviation in time until pore formation of G-PET film degraded with $27.6 \mu \mathrm{g} \cdot \mathrm{mL}^{-1} \mathrm{PHL7}$. Six samples were run simultaneously and deviated only by a maximum of $20 \mathrm{~min}$ in the first pore formation 
event. Four of the six samples deviated only by $\pm 1 \mathrm{~min}$. Left: Overview of the change in R2 over time, Right: Close-up of the breakthrough time.

$225 \mu \mathrm{m}$ PET film thickness

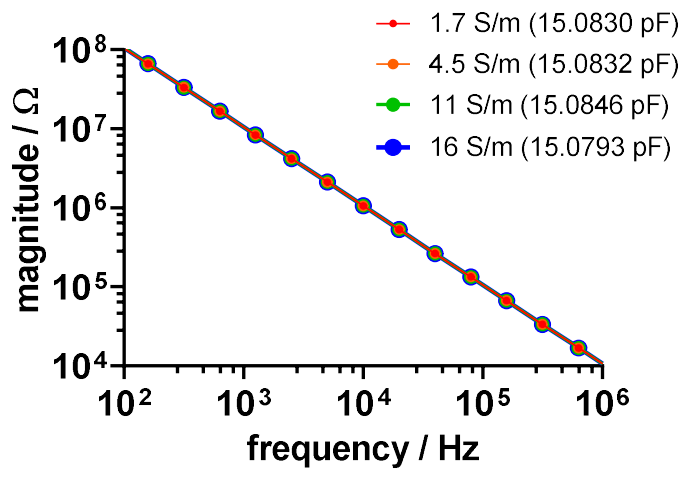

$12 \mu \mathrm{m}$ PET film thickness

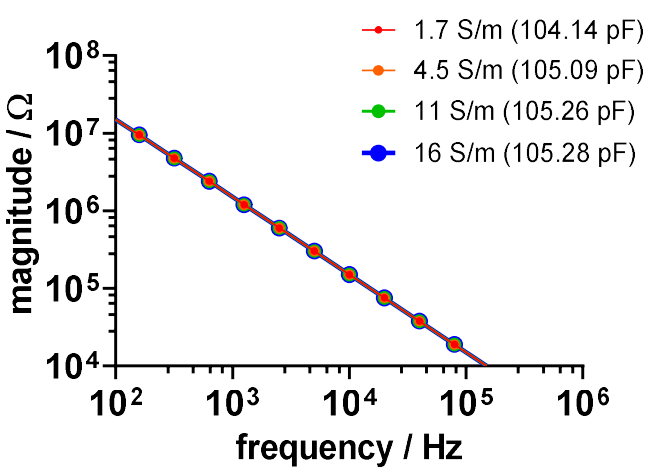

Figure S12: FEM simulation based analysis of solvent conductivity influence on the PET film capacitance. The PET film was simulated with dimensions of $4.3 \times 9.1 \mathrm{~mm}^{2}$, and thickness of $225 \mu \mathrm{m}$ (left) as well as $12 \mu \mathrm{m}$ (right), a relative permittivity of 3.3 and different solvent conductivities according to the experimental evaluated potassium phosphate buffer concentration of $0.1 \mathrm{M}$ $\left(1.7 \mathrm{~s} \cdot \mathrm{m}^{-1}\right), 0.3 \mathrm{M}\left(4.5 \mathrm{~S} \cdot \mathrm{m}^{-1}\right), 1 \mathrm{M}\left(11 \mathrm{~s} \cdot \mathrm{m}^{-1}\right), 2 \mathrm{M}\left(16 \mathrm{~S} \cdot \mathrm{m}^{-1}\right)$ (see Fig. 3C). The conductivity of the used buffer solutions was determined with a SevenExcellence $\mathrm{pH} /$ Cond/Do meter S479-K and the Cond probe InLab 738 ISM (Mettler Toledo, USA). From the FEM simulation derived impedance magnitude spectra, the appropriate capacitances (shown in brackets) were determined by equivalent circuit fitting. 


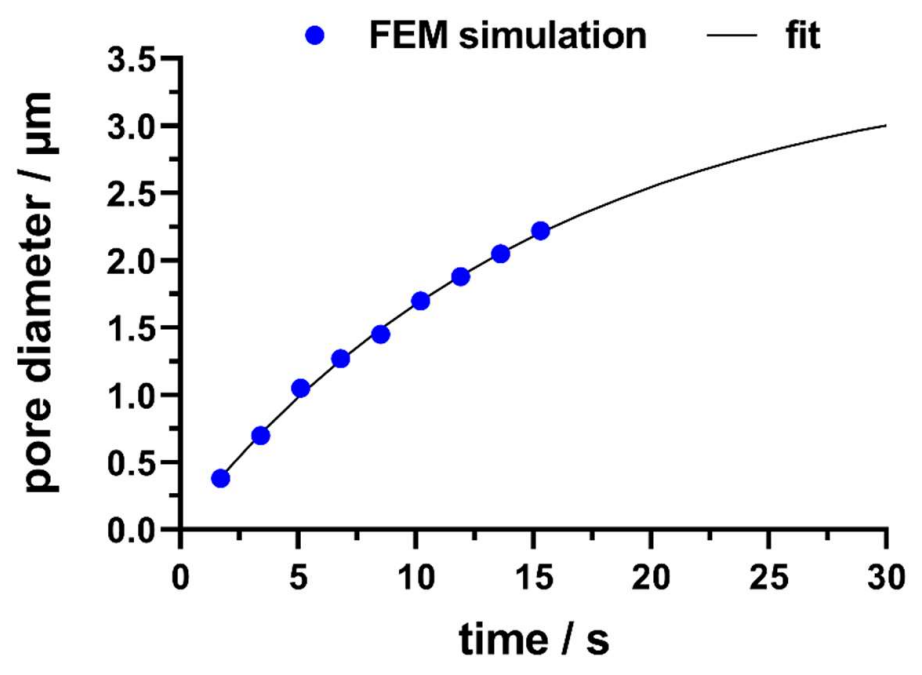

Figure S13: Time dependent increase of Pore 1 diameter. FEM simulation were performed for one pore with an increase in pore diameter to fit the impedance spectra derived R2 values according to the experimental data set of the black graph in Fig.4A. Due to the occurrence of a second pore after $17 \mathrm{~s}$, the fitted data of the first $15 \mathrm{~s}$ were used for fitting and calculation of the diameter of Pore 1 for the following time points. 


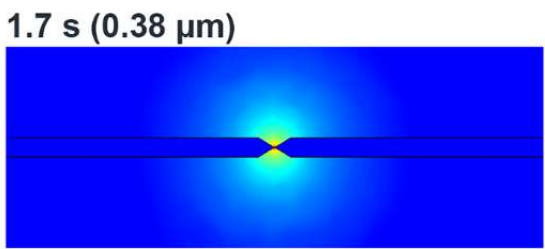

$5.1 \mathrm{~s}(1.05 \mu \mathrm{m})$

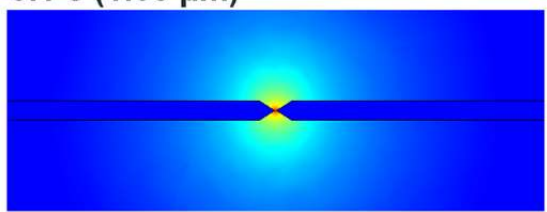

$8.5 \mathrm{~s}(1.45 \mu \mathrm{m})$

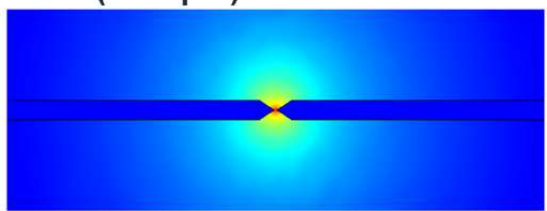

$11.9 \mathrm{~s}(1.88 \mu \mathrm{m})$

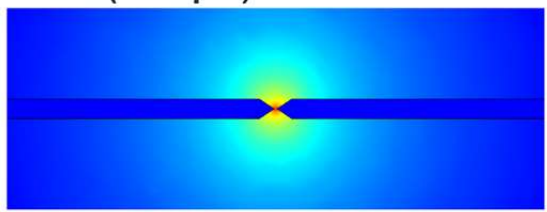

$15.3 \mathrm{~s}(2.22 \mu \mathrm{m})$

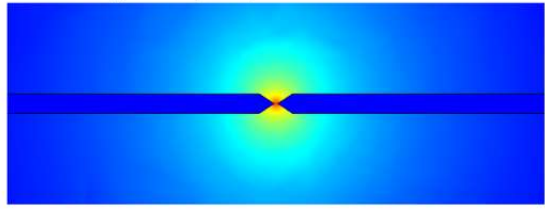

$17.0 \mathrm{~s}(2.34 \mu \mathrm{m} \mid 0.25 \mu \mathrm{m})$

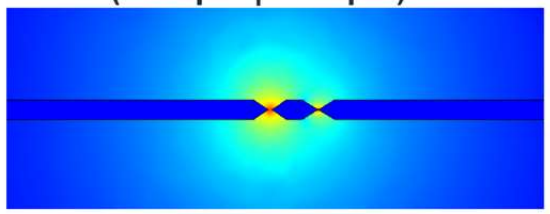

$18.7 \mathrm{~s}(2.46 \mu \mathrm{m} \mid 1.9 \mu \mathrm{m})$

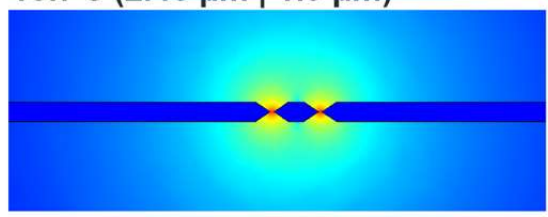

$20.4 \mathrm{~s}(2.57 \mu \mathrm{m} \mid 3.3 \mu \mathrm{m})$

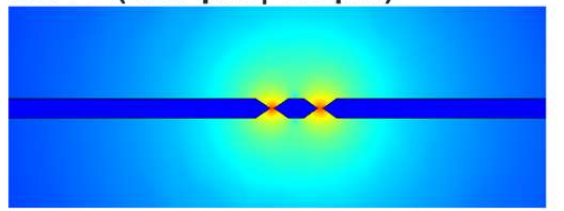

$23.8 \mathrm{~s}(2.76 \mu \mathrm{m} \mid 6.39 \mu \mathrm{m})$

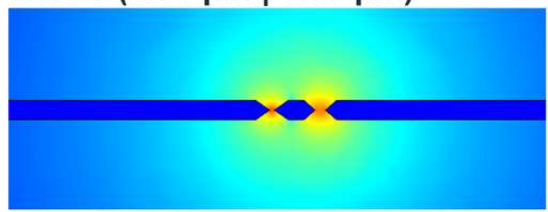

$27.2 \mathrm{~s}(2.9 \mu \mathrm{m} \mid 8.6 \mu \mathrm{m})$

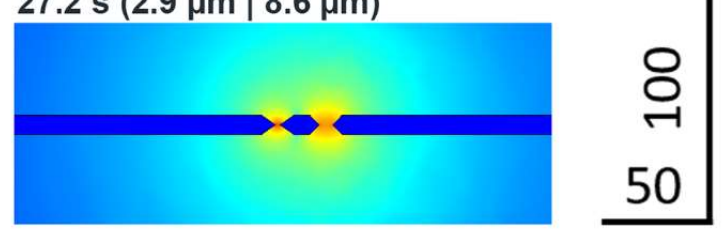

Figure S14: FEM simulation of multiple pore formations. The PET film was simulated with dimensions of $4.3 \times 9.1 \mathrm{~mm}^{2}$ and a thickness of $12 \mu \mathrm{m}$ according to the equivalent circuit derived capacitance at the time of pore formation. Current density for $1.26 \mathrm{kHz}$ at distinct times after first detected pore formation event are shown with pore diameters in brackets. 